\title{
@SirBill: the power of social media to transform medical education
}

\author{
Jonathan Sherbino, ${ }^{1,2}$ Jason R Frank ${ }^{2,3}$
}

If William Osler were to visit today the hospitals in Montreal, Philadelphia, Baltimore and Oxford where he taught in the latter part of the 19th century, he would encounter an array of innovations -robotic surgery, genomic sequencing, organ transplantation, to name a fewthat formed no part of the medical landscape of his own time. On the other hand, the system of medical education used at those same hospitals would be familiar to Sir William. He would recognise the model of specialist residencies that he (along with the surgeon William Halsted and others) introduced, and he would no doubt be gratified to see that his success in moving clinical education from the abstractions of the lecture hall to the realities of the bedside has endured. ${ }^{1}$

It is striking that, while scientific discovery and technological innovation moved diagnostic and therapeutic practice forward by leaps and bounds, the model of medical education has remained essentially unchanged over the past century. More recently, however, the uptake of the latest wave of internet-based media by individuals, groups, institutions and enterprises has been rapid and inexorable, and the characteristics of these technologies - 'networked', 'instantaneous', 'crowdsourced', 'social'-have had a profound impact on culture and behaviour. For medical educators, the question is not whether these 'social media' will be applied in their field, but how. Indeed, the emergence of these technologies presents an opportunity to reimagine the future of medical education.

Social media use internet-based communications technology to engage geographically dispersed groups or individuals to create or share content related to a common theme, thus forming a 'virtual' community. Commonly used modes include blogs, microblogs (eg, Twitter), wikis, networking websites (eg, Facebook),

\footnotetext{
${ }^{1}$ Division of Emergency Medicine, McMaster University, Hamilton, Ontario, Canada; ${ }^{2}$ Royal College of Physicians and Surgeons, Ottawa, Ontario, Canada; ${ }^{3}$ Department of Emergency Medicine, University of Ottawa, Ottawa, Ontario, Canada
}

Correspondence to Dr Jonathan Sherbino, Hamilton General Hospital, McMaster Clinic, 237 Barton St E, Hamilton, Ontario, Canada L8L 2X2; sherbino@mcmaster.ca podcasts and videocasts. ${ }^{2}$ The use of social media in medical education is a departure from precursor forms of electronically enabled learning (e-learning) such as computer-based learning and web-based learning. Simply defined, computer-based learning delivers stand-alone multimedia presentations $^{3}$ and does not require internet connectivity; examples include prepackaged video presentations and virtual patient simulations. Web-based learning delivers information from the 'teacher' to the learner by such means as online courses, email communications and website-hosted media (eg, videos). ${ }^{4}$ Definitions of types of technology-enabled learning have been applied inconsistently in the literature, and have been criticised for failing to distinguish between the instructional method (eg, clinical scenarios requiring self-assessment) and the platform used (eg, YouTube video). ${ }^{5}$ Although the technologies used by social media can be similar to those used in webbased learning, they are distinct in their ability to connect the learner to content, and to a virtual community of learners who share and develop related content as part of the educational process.

The rapid growth and adoption of social media outside of medicine (by the end of 2013, Facebook and Twitter had more than 1 billion users worldwide) ${ }^{67}$ forecasts disruptive innovation in medical education: that is, they have the potential to displace existing structures of medical education in unanticipated ways. The 'Free Open Access Meducation' (FOAM) movement for example, demonstrates how social media can be applied to change the delivery of medical education resources. ${ }^{8}$ FOAM uses social networks, aligned along clinical specialties, to freely share resources, many of which are locally produced. The digital connectivity of these geographically dispersed networks allows significant penetration of resources beyond the local sites that developed them. (For example, one emergency medicine blog, which serves as a FOAM clearing-house, has more than 12 million unique visits per year. $)^{9}$ Free access to a large pool of education resources empowers students and teachers (particularly individuals in resource-poor areas of the world) to focus on learning rather than content development.
Building on the success of the Khan Academy (http://www.khanacademy.org), a free resource for online learning, medical educators are also reorienting classroom-based learning by means of the 'flipped classroom'. In this model, core concepts are introduced and discussed through online social networks in advance of scheduled inperson instruction. In place of traditional lectures, class time is devoted to tailored discussion with the instructor to address points of confusion arising from the core material and to explore more complex ideas that arise. ${ }^{10}$ Curating the best social mediadistributed resources according to clinical topic and type of learner will further optimise the flipped classroom, freeing up local faculty from developing, in a laborious, parallel fashion around the world, nearly identical common resources.

Finally, the use of 'digital badges'-electronic insignia associated with a learner (on a web profile, for example) to indicate that he or she has mastered a particular topic or skill-may present an opportunity for medical educators to use social media to promote mastery in a subject area. ${ }^{11}$ Digital badges could be embedded with the standard required and provide evidence of each learner's achievement of competence in a particular domain. The democratic and transparent nature of social media has the potential to promote the value of digital badges.

Of course, social media cannot answer every need in medical education. The rapid explosion of resources requires content curation and the careful assessment of quality, lest the explosion of resources facilitated by social media contribute to an unmanageable inflation of curricula. ${ }^{4}$ Moreover, to the novice or advanced beginner, the flat democracy of social media may result in the false acceptance of all resources as equal. Certainly, this was a frequent criticism of early Wikipedia entries. However, the current standard for editing Wikipedia entries employs a hierarchical democracy by which editors must demonstrate editorial competence and their proficiency in a content area before being permitted to submit or alter an entry, and similar standards should be applied to resources delivered through social media.

Social media should not be viewed as a replacement for local teachers and educators. Teachers are still required to diagnose and address gaps in the knowledge and abilities of individual learners and to serve as their role models. Educators are still required to tailor learning and 
curricula to the local environment and the needs of learners.

Finally, it should never be assumed that social media can replace the most fundamental and important learning opportunity: the patient encounter. The debates that surrounded the introduction of medical simulation two decades ago parallel current debates about the use of social media in education. We need to continually remind the medical education community that the most important (and foundational) learning for physicians happens in the clinical environment. In the 19th century, Osler led medical students out of lecture halls and into the hospital wards. The 21 st century educators should not send them back to an exclusive virtual classroom. Instead, opportunities for learning can extend to a network that spans the world. If Osler were alive today, we're confident he would be on Twitter @SirBill.

Contributors Both authors contributed equally to the concept, writing and editing of this article.

Competing interests None.
Provenance and peer review Commissioned; internally peer reviewed.
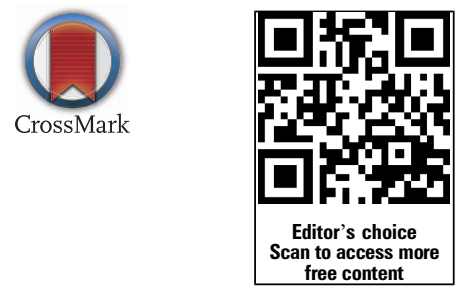

To cite Sherbino J, Frank JR. Postgrad Med J 2014;90:545-546.

Received 27 June 2014

Revised 4 August 2014

Accepted 7 August 2014

Published Online First 2 September 2014

Postgrad Med J 2014;90:545-546.

doi:10.1136/postgradmedj-2014-132868

\section{REFERENCES}

1 Roland GG. Sir William Osler. In: Dictionary of Canadian Biography, Vol. 14. Toronto/Québec: University of Toronto/Université Laval, 1998. http:// www.biographi.ca/en/bio/osler_william_14E.html (accessed 24 Jun 2014).

2 Cheston CC, Flickinger TE, Chisolm MS. Social media use in medical education: a systematic review. Acad Med 2013;88:893-901.
3 Ruiz JG, Mintzer MJ, Leipzig RM. The impact of E-learning in medical education. Acad Med 2006;81:207-12.

4 Cook DA, Levinson AJ, Garside S, et al. Internetbased learning in the health professions: a meta-analysis. JAMA 2008;300:1181-96.

5 Cook DA, Garside S, Levinson AJ, et al. What do we mean by web-based learning? A systematic review of the variability of interventions. Med Educ 2010;44:765-74.

6 Kiss J. Facebook's 10th birthday: from college dorm to 1.23 billion users. The Guardian 4 Feb 2014 http://www.theguardian.com/technology/2014/feb/ 04/facebook-10-years-mark-zuckerberg (accessed 24 Jun 2014).

7 Holt R. Twitter in numbers. The Telegraph, $21 \mathrm{Mar}$ 2013. http://www.telegraph.co.uk/technology/twitter/ 9945505/Twitter-in-numbers.html (accessed 24 Jun 2014).

8 Nickson C. FOAM. Life in the Fastlane [blog], 6 Feb 2014. http://lifeinthefastlane.com/foam/ (accessed 24 Jun 2014).

9 Cadogan M, Thomas B, Chan TM, et al. Free Open Access Meducation (FOAM): the rise of emergency medicine and critical care blogs and podcasts (2002-2013). Emerg Med J. Published Online First: 19 Feb 2014. doi:10.1136/ emermed-2013-203502

10 Sherbino J, Chant T, Schiff K. The reverse classroom: lectures on your own and homework with faculty. CJEM 2013;15:178-80.

11 Mehta NB, Hull AL, Young JM, et al. Just imagine: new paradigms for medical education. Acad Med 2013;88:1418-23. 